\title{
CONCEPÇÕES DE SUCESSO E FRACASSO ESCOLAR NA PERSPECTIVA DOS ALUNOS DE EDUCAÇÃO DE JOVENS E ADULTOS.
}

\author{
Ana Cristina Fernandes Ventura ${ }^{1}$
}

\begin{abstract}
Resumo: Este estudo objetiva identificar as concepções de sucesso e fracasso escolar para alunos da Educação de Jovens e Adultos (EJA). Participaram 10 estudantes do EJA dos municípios de Imbé e tramandaí, localizados na região do Litoral Norte do Rio Grande do Sul. Utilizou-se questionário sociodemográfico e roteiro de entrevista e a análise proposta foi a qualitativa dos dados (análise de conteúdo). Os resultados evidenciaram que os alunos acreditam que esses fenômenos educacionais devem ser visto com um olhar amplo, não taxativo, restritivo, para que assim não se torne pejorativo e generalizado, sendo assim o sucesso e fracasso escolar ainda necessitam de estudos que desconstruam e reconstruam esse pensar.
\end{abstract}

Palavras-Chaves: sucesso; fracasso escolar; educação; jovens e adultos.

\section{CONCEPTIONS OF SCHOOL SUCCESS AND FAILURE FROM THE PERSPECTIVE OF YOUTH AND ADULT EDUCATION STUDENTS.}

\begin{abstract}
This study aims to identify conceptions of school success and failure from students in Youth and Adult Education (EJA). Ten EJA students from the cities of Imbé and Tramandaí, located in the North Coast region of Rio Grande do Sul, participated in this study. A sociodemographic questionnaire and an interview script were used and the proposed analysis was a qualitative content analysis. The results showed that students believe that these educational phenomenon should be viewed with a broad, non-restrictive look, so that it does not become a pejorative and widespread, so school success and failure still need studies that deconstruct and reconstruct this think.
\end{abstract}

\footnotetext{
${ }^{1}$ Acadêmica do Curso de Bacharelado em Psicologia da UNICNEC. 
Keywords: success; school failure; education; young and old.

\section{INTRODUÇÃO}

Atualmente temos a Educação de Jovens e Adultos - EJA, uma modalidade de ensino destinada a uma população que não teve a oportunidade de frequentar a escola regular, abrangendo a educação básica, em suas etapas fundamental e médio. Essa população é bastante diversificada e singular, formada por cidadãos que tiveram ingresso precoce no mercado de trabalho (PICONEZ, 2002), evasão e reprovações ao longo do seu histórico escolar (NEGREIROS et al, 2017). Segundo Lopes e Teixeira (2012, p.8) "Na história de muitos alunos, que saem da escola sem terem concluído o percurso escolar obrigatório na idade prevista na legislação, o insucesso escolar é acompanhado da ausência de projectos de vida.", porém os alunos ao serem inseridos no EJA têm a oportunidade de enfrentar o fracasso escolar, abrindo novas possibilidades de melhoria de vida.

Quanto aos termos Sucesso e Fracasso Escolar, podemos dizer que são geralmente

utilizados para indicar alguns fenômenos educacionais, estes estão relacionados ao desempenho escolar dos alunos, seus comportamentos, frequência e permanência. O Fracasso Escolar é geralmente evocado para apontar o baixo rendimento do aluno, aquisição insuficiente dos conhecimentos e habilidades, defasagem na relação idade-série, reprovação, repetência, interrupção escolar sem a obtenção de um certificado, entre outras designações com conotações negativas (ZAGO, 2011), o Sucesso por sua vez, vem como o oposto desses itens. Uma das grandes críticas refere-se na utilização destes termos, pois há risco de serem usados pejorativamente ou de forma que rotule os alunos. De acordo com Pozzobon, Mahendra e Marin (2017), algumas pesquisas indicam que ao rotular um aluno, sua autoestima e autoconfiança podem ser abaladas, tal como a diminuição da motivação para estudar e produção de comportamentos disfuncionais. Outros resultados também mostraram que os que têm baixo desempenho são mais propensos a manifestar problemas psicossociais (MILLONES; LEEUWEN; GHESQUIÈRE, 2012).

Foi realizado um projeto global lançado pela Organização para a Cooperação e o Desenvolvimento Econômico (OCDE) em 2010, com o objetivo de ajudar os países a melhorar suas políticas e práticas, assim reduzindo o fracasso nas escolas. Através dele foi possível constatar que o insucesso escolar pode prejudicar uma pessoa por toda sua vida, 
suscitando dificuldades em sua vida profissional, principalmente ao que concerne às questões financeiras. Logo as consequências do fracasso escolar também devem ser motivos de preocupação para a sociedade, já que podem ocasionar o aumento da criminalidade e a necessidade de gastos adicionais de saúde e de assistência social.

Considerando estes fatores, e que fenômeno presente vêm se perpetuando há muito tempo, bem como alguns problemas de base se torna evidente a relevância da produção de estudos sobre o fracasso e sucesso escolar e suas atribuições, no intuito de uma melhor compreensão sobre o tema e futuramente buscar soluções afins de amenizar o índice de alunos com insucesso escolar. Para Piconez (2002) "Pensar soluções para tais problemas passa pela questão da cidadania, entendida como participação crescente na vida social, política e econômica do país" É preciso salientar que ao iniciar essa busca é necessário um olhar amplo, pois é preciso levar em conta que somos seres biopsicossociais.

Assim por meio deste trabalho buscou-se Identificar as concepções de sucesso e fracasso escolar para alunos da Educação de Jovens e Adultos; Investigar os principais aspectos que levam os alunos a inserir-se no programa do EJA; Analisar a percepção dos discentes quanto o envolvimento escolar na produção do sucesso ou fracasso. Para isso foi utilizado como modelo de pesquisa o método qualitativo, usando como principal instrumento de coleta de dados entrevistas semi-estruturadas em alunos inseridos no programa de Educação de Jovens e Adultos dos municípios de Imbé e Tramandaí, localizado no Litoral Norte do Rio Grande do Sul.

\section{FUNDAMENTAÇÃO TEÓRICA}

\subsection{A educação na contemporaneidade}

Por muito tempo o direito à educação "tradicional" era destinada a uma pequena minoria, privilégio da classe burguesa. Com o passar das décadas o olhar para o ensino mudou significativamente, Gadotti (2000) considera que a educação, no século XX, tornou-se permanente e social, e que não limita a educação a apenas um período específico, oportunizando o sujeito ao longo da vida. O autor não descarta, obviamente, as problemáticas existentes, como por exemplo os desníveis entre regiões e países, e diferentes classes, mas ressalta os grandes avanços adquiridos até então. 
Ao que concerne os avanços, atualmente é garantido por lei o acesso e qualidade universal de ensino, consta no Art. 208. da legislação brasileira a afirmação sobre a responsabilidade do poder público para com a educação, em especial a oferta gratuita do ensino básico, até mesmo para aqueles que não tiveram acesso na idade própria. É notável também as mudanças relacionadas à política de educação especial no Brasil, no qual houve a implementação da inclusão.

Encontra-se na resolução CNE/CEB n ${ }^{0}$ 2, de 11 de setembro de 2001, que:

Os sistemas de ensino devem matricular todos os alunos, cabendo às escolas organizar-se para o atendimento aos educandos com necessidades educacionais especiais, assegurando as condições necessárias para uma educação de qualidade para todos. Os sistemas de ensino devem conhecer a demanda real de atendimento a alunos com necessidades educacionais especiais [...] (BRASIL, 2001, art.2 $2^{\circ}$ ).

Porém, mesmo com todo o progresso educacional, ainda existem muitos desafios a serem enfrentados, como por exemplo o fator socioeconômico que grande parte do país se encontra, no qual leva-se em conta que a distribuição de renda e da riqueza no país pode determinar o acesso e a permanência dos estudantes na escola (CURY, 2002), bem como o carecimento de melhorias no tocante a uma aprendizagem mais efetiva. (DOURADO; OLIVEIRA , 2009).

A percepção construída sobre a escola está altamente relacionada com a visão de que é a partir dela que ocorrerá a inserção do sujeito na sociedade, Damasceno, Costa e Negreiros (2016, p. 9) ressaltam que ''atualmente, no modelo capitalista, em que todos se encontram submersos, há uma enorme expectativa e cobrança no que tange à educação, visando à inserção no mercado de trabalho", esta afirmativa faz muito sentido ao analisarmos as expectativas depositadas a escolarização, tornando perceptível a pressão social no que tange ao rendimento escolar.

\subsection{Concepções sobre sucesso e fracasso escolar}

A expressão Sucesso e Fracasso escolar têm sido utilizados para se referir ao alto ou baixo rendimento indivíduos no que compete a educação institucional, sendo este rendimento 
muitas vezes relacionados pela sociedade como um fator determinante para o futuro profissional.

Há um destaque especial ao que se refere Fracasso escolar, pois segundo dados do IBGE em 2016 as taxas relativos a reprovação por série (8,3\%), abandono escolar a nível fundamental $(1,9 \%)$ e reprovação por série $(11,9 \%)$, abandono escolar $(6,6 \%)$ a nível médio, mostram que apesar de haver uma redução em comparação aos anos passados, continuam significativas e preocupantes. Devido a persistência desses dados é compreensível a preocupação da educação e psicologia no que tange os motivos atribuídos para a produção do fracasso educacional. Damasceno, Costa e Negreiros (2016) defendem que para analisar essas atribuições é necessário um olhar amplo as diversas esferas que envolvem o aluno e o contexto não buscando culpados mas elementos contribuintes para a situação.

Um estudo realizado por Asbahr e Lopes (2006) faz uma analise sobre diversos aspectos que acarretam do sucesso e insucesso escolar, as hipóteses surgiram a partir de discursos dos professores e alunos de uma escola pública municipal da cidade de São Paulo, no qual foi possível dividir em quatro grandes grupos representativos, sendo eles:

- causas biológicas, tais como Idade mental inferior à cronológica, problemas neurológicos, problema fonoaudiológico, problema de audição, Problema de visão;

- causas familiares, como falta de interesse da família, falta de incentivo, situação familiar complicada como separação dos pais, casos de violência domésticas e negligência familiar.

- causas culturais, por exemplo falta de oralidade, carência econômica, carência afetiva, falta de motivação e interesse.

- causas emocionais, dentro deles o trauma, vida sofrida, bloqueio e a agressividade.

De acordo com estas hipóteses é possível perceber que todas estão centradas de certa forma no aluno, isso trata-se de uma tendência à culpabilização individual, sendo esta persistente nas práticas educativas atuais, ocultando a responsabilidade do professor e excluindo outros processos relevantes (NEGREIROS et al, 2017)

Zago (2011, p. 59-60) relata que:

Acompanhando, durante um período relativamente longo de tempo, a situação escolar dos filhos de famílias de baixa renda, foi possível constatar alunos que interrompem seus estudos durante o ensino fundamental, mesmo quando os 
resultados são favoráveis nas avaliações. Em alguns casos, mas não sempre, a razão dessa interrupção está relacionada à necessidade do trabalho para auxiliar na sobrevivência familiar ou outra também não relacionada com o desempenho escolar.

Para o autor, logo a denominação de fracasso escolar encobre processos que não são necessariamente de um aluno que não aprende, que não tem êxito na escola, mas sim toda uma questão socioeconômica e de desigualdade, que já sabemos estar presentes na maioria das regiões brasileiras. Com base nestas revisões podemos pensar nessas atribuições, não como elementos separados mas como um conjunto de fatores, sendo o insucesso escolar apenas um sintoma.

Enfatiza-se assim, que o fracasso escolar não deve ser considerado apenas como um problema educacional, pois pode repercutir em situações individuais e sociais por este motivo a preocupação com este fenômeno vai além da educação, Pezzi, Donelli e Marin ( 2016) argumentam que a psicologia também está presente nesta discussão, mais diretamente no que se trata de prevenção e tratamento .

\subsection{Educação de Jovens e Adultos}

A educação como direito universal é um marco recente no país. Um dos programas implementados em busca dessa universalização é a Educação de jovens e adultos (EJA), este é destinado aqueles que não tiveram acesso a escola na idade própria, sendo um "mecanismo que viabiliza a reinserção de pessoas excluídas precocemente da escola, contribuindo na efetivação da cidadania' (CAVALCANTE; CARDOSO, 2016 p. 159). Vale lembrar que o EJA é uma forma peculiar da educação básica abrangendo o ensino fundamental e médio, logo é responsabilidade do poder público.

Foi necessário muitos movimentos de lutas e desejos da educação popular para que a educação de jovens e adultos ganhasse espaço na sociedade. Almeida e Corso (2015, p. 1286) em seu estudo sobre os aspectos históricos da EJA trazem que a primeira iniciativa pública, que objetiva especificamente o atendimento de adolescentes e adultos, ocorreu apenas em 1947 com o lançamento da Primeira Campanha Nacional de Educação de Adolescentes e Adultos (CEAA), iniciativa do Ministério da Educação e Saúde e coordenada por Lourenço Filho. O foco dessa iniciativa era levar essa educação aos brasileiros de cidades e zonas rurais, afins de incentivar o desenvolvimento social e econômico. Porém existia muito 
preconceito com os adultos, associando o analfabetismo com a ignorância ou incapacidade, além disso tinha-se a ideia de que ensinar adultos era muito mais fácil que ensinar crianças, logo não exigiam uma especialização da área, podendo qualquer pessoa alfabetizada se voluntariar, sendo assim eram tratados de forma infantilizada e com educadores não especializados (MEDEIROS, 1999).

A partir de 1958 com a realização do II Congresso Nacional de Educação de Adultos no Rio de Janeiro que iniciou a problematização quanto ao método de ensino para adultos, surgindo nessa mesma época o pedagogo e idealizador Paulo Freire, o mesmo implantou e defendeu uma nova metodologia de alfabetização para adultos e trouxe uma revolução educacional, sendo reconhecido internacionalmente pelo seu trabalho e seus ideais (CENTURION; GOMES, 2015). Dentre suas convicções Freire considera o EJA “como uma ação que deve aproveitar os conhecimentos dos sujeitos envolvidos, bem como propiciar seu desenvolvimento tornando-os responsáveis pelo seu próprio aprendizado" (Gomes, 2015 p. 5) Atualmente, após muita luta a EJA é ocupado por educandos que apesar de não terem concluído os estudos na idade prevista, têm a possibilidade de retornar ao ambiente acadêmico e mudar seu percurso de uma forma adequada, justa e coerente com suas necessidades e demanda .

Carvalho (2009) cita alguns fatores que contribuem para a migração dos jovens e adultos à EJA, sendo eles a evasão, repetência, que ocasionam a defasagem entre a idade/série, a possibilidade de aceleração de estudos e a necessidade do emprego. É nesse retorno à escolarização que surge a possibilidade de uma nova significação na vida desses jovens e adultos.

É conveniente destacar que os profissionais que atuarão nesta categoria devem considerar e valorizar os conhecimentos adquiridos ao longo da vida de cada educando (CAVALCANTE; CARDOSO, 2016), exercendo sua atividade com sensibilidade, respeitando a realidade social dos estudantes, de modo que reduza o abismo cultural entre aluno e professor. Os alunos desta categoria têm em seu histórico uma experiência com o insucesso escolar, que por consequência traz marcas significantes para a vida do sujeito, como a desmotivação, baixa estima, e falta de confiança em si mesmo, é dever do docente estimular o potencial e a autoestima desses indivíduos (GOMES, 2015). É nesse estímulo que é possível promover a auto-eficácia, aumentando a probabilidade de sucesso e prevenindo uma possível futura e repetida evasão. 
Franco (2009, p. 327) destaca que "reforçamento positivo produz uma autoestima positiva, mesmo em condições precárias de ensino aprendizagem'. Por este motivo é relevante destacar o conceito de auto-eficácia, que caracteriza-se como o julgamento que as pessoas têm sobre suas próprias capacidade para executar e organizar ações, proporcionando a base para a motivação, bem estar e realizações pessoais (BANDURA; AZZI; POLYDORO; 2006), logo exerce um papel na determinação do comportamento e do pensamento do sujeito, tendo forte influência para a resiliência.

\section{METODOLOGIA}

\subsection{Participantes}

Participaram da pesquisa 10 estudantes inseridos nos programas públicos (noturno) da Educação de Jovens e Adultos/EJA, pertencentes ao último ciclo, dos municípios de Imbé e Tramandá, localizado no Litoral Norte do Rio Grande do Sul. Os participantes foram escolhidos a partir de indicação das instituições provedoras do programa de cada município.

Há a prevalência de mulheres $(70 \%)$, brancos $(70 \%)$, negros $(20 \%)$ e pardos $(10 \%)$, com a idade média de 19 anos (variando de 18 a 57 anos); destes, 80\% são solteiros, e os demais viúvos (10\%); em união estável (10\%). 50\% têm filhos, declaram o nível socioeconômico como médio (80\%), e baixo (20\%). Apenas $10 \%$ possui alguma necessidade especial, e 20\% alguma doença crônica. Quanto ao trabalho, 30\% exercem atividades remuneradas, $30 \%$ consideram-se do lar e $40 \%$ estudantes.

\subsection{Instrumentos de coleta de dados}

A construção dos dados foi realizada por meio de dois instrumentos, o questionário sociodemográfico e o roteiro de entrevista semiestruturada, com perguntas semi-abertas organizadas em roteiro tópico. Levou-se em conta que essa técnica por ter um índice de respostas bem mais abrangente e espontâneas (BONO; QUARESMA, 2005) produziria uma melhor amostra da população de interesse.

No questionário sociodemográfico, foram solicitadas informações como idade, sexo, estado civil, renda mensal, ciclo da EJA, entre outros. E o roteiro de entrevista 
semiestruturada conteve algumas questões geradoras para subsidiar a investigação: motivo de desistência dos estudos, caso nunca tenha desistido, o porquê de estar inserido na Educação de Jovens e Adultos; qual a motivação para voltar a estudar e/ou permanecer no EJA; as percepções quanto ao sucesso e fracasso escolar; expectativas em relação ao futuro, melhorias de qualidade de vida através da conclusão do ensino básico; a percepção quanto o envolvimento escolar na produção do sucesso ou fracasso educativo.

\subsection{Análise de dados}

A presente proposta utilizou uma análise qualitativa dos dados (análise de conteúdo) dos depoimentos dos 10 entrevistados. A análise de conteúdo tem como objetivo extrair sentido dos dados obtidos (CRESWELL, 2007), esperando assim permitir a inferência de conhecimentos relativos às questões norteadoras do estudo. A análise obedeceu as três fases conforme elencados por Bardin (2006) : 1) pré-análise, 2) exploração do material e 3) tratamento dos resultados, inferência e interpretação.

Inicialmente, foi feito a organização do material a ser analisado, por exemplo as entrevistas que foram transcritas, para facilitar a leitura e a identificação dos temas pré-definidos no roteiro-tópico e outros temas emergentes dos sujeitos. As unidades significativas (palavras, termos, expressões pertinentes ao tema) foram identificadas e transcritas conservando-se a linguagem do sujeito e, na etapa posterior, quando ocorreu a descrição analítica foram transformadas em linguagem proposta pelo pesquisador no intuito de facilitar comparações.

A etapa seguinte consistiu na exploração do material, que possibilitou a riqueza das interpretações e inferências (MOZZATO; GRZYBOVSKI, 2011), neste momento foi realizado a descrição analitica do material coletado, e também a identificação de possíveis padrões, contrastes e relações entre os depoimentos.

Por fim o tratamento dos resultados culminou nas interpretações inferenciais, sendo construído um entendimento das informações organizadas na etapa anterior. Isto é, as deduções lógicas ou inferências obtidas a partir das categorias permitiram a identificação das questões relevantes contidas no conteúdo das entrevistas.

\subsection{Considerações éticas}


O projeto foi submetido ao Comitê de Ética em Pesquisa (CEP) do Centro Universitário Cenecista de Osório, com o propósito de averiguar os parâmetros éticos de pesquisa, no qual foi aprovado. Com a autorização, as informações foram coletadas de forma individual de acordo com as indicações das instituições, sem qualquer prejuízo para as pessoas envolvidas,

Os dados coletados ficarão sob a guarda da pesquisadora (Ana Cristina Fernandes Ventura) e de seu orientador (Zuleika Leonora Schmidt Costa) por cinco anos, sendo garantido seu sigilo e confidencialidade.

Todos os participantes foram inteirados dos objetivos da pesquisa pelo pesquisador e orientados e convidados a assinar um Termo de Consentimento Livre e Esclarecido - TCLE .

\section{RESULTADOS E DISCUSSÃO}

A análise de resultados constitui-se por 10 entrevistas realizadas com alunos inseridos no programa de Educação de Jovens e Adultos, de duas escolas, uma localizada no Município de Imbé e outra em Tramandaí, Região Litorânea do Rio Grande do Sul.

\subsection{Fatores que levam a inserção no Programa de Educação de Jovens e Adultos}

Quando indagados os sujeitos sobre os motivos que levaram sua inserção ao programa de educação de jovens e adultos, três fatores se destacaram, sendo eles: (a) Praticidade; (b) Busca de aprimoramento para melhor oportunidade de emprego; (c) Concluir o ensino básico para iniciar o ensino superior.

Grande parte dos entrevistados citaram a praticidade que o EJA proporciona para os alunos como um fator essencial para sua inserção no programa, como retrata as seguintes falas:

“Acho que por ser uma coisa mais rápida, mesmo eu achando 21 anos nova ainda, eu achei necessário entrar pra terminar logo." (Participante 4)

“É melhor, eu tava atrasada.” (Participante 8) 
As falas se justificam pela metodologia da modalidade que acontece em módulos de seis meses que equivalem a cada ano que ainda não foi cumprido, ou seja se o aluno não concluiu os três anos do ensino médio, logo no EJA poderá concluir em um ano e meio, tornando-se assim mais rápido para a conclusão do ensino.

Os alunos relatam também que o programa em ambos os municípios ocorrem no turno da noite, sendo de mais fácil acesso já que um número considerável de alunos têm compromissos durante o dia, seja com o trabalho ou com família, como se pode observar nas falas a seguir:

"Eu tava no segundo do regular, eu não queria sair, aí fiz 18 e apareceu oportunidades de emprego [...] eu decidi que ia começar a trabalhar então fui para o EJA a noite. "(Participante 6)

"Porque pra mim é mais prático, mais rápido, eu tenho um filho e preciso ser prática." (Participante 7)

A metodologia do EJA já foi pensada para atender um público específico, Gomes (2015) justifica que o programa é composto por indivíduos que possuem experiências já adquiridas, que vivem no mundo do trabalho e têm responsabilidades familiares e sociais e isso deve ser levado em contado e respeitado.

Além da praticidade, outra questão trazida pelos entrevistados é o estudo como qualificador para a inserção no mercado de trabalho. Na sociedade, estudar geralmente está associado ao o ascender social e financeiro, realmente permitindo uma melhor colocação no mercado de trabalho (NAIFF e MONTEIRO, 2008). Um dos participantes relata sua experiência e afirma o quanto o ensino incompleto o prejudicou nessa área:

“Já perdi um serviço por não ter o ensino completo [...] tive que voltar pra aula pra terminar, e agora com o tempo tentar de novo a vaga em que eu trabalhava." (Entrevistado 1)

O mesmo complementa que o estudo possibilita uma vaga em serviços com salário superior, e carga horária mais flexível, e sem ele é quase impossível ter uma boa qualidade de vida. E é em busca de qualidade de vida que muitos retornam a escola, buscando dar continuidade aos estudos, pois completando o ensino médio poderão dar início a uma nova fase na vida, ingressando em uma graduação ou curso técnico. 
Eu tenho muitos objetivos, eu quero ser mais estudada, fazer faculdade de fisioterapia, quero que meus filhos tenham orgulho de mim e se espelhem. (Participante 10)

"Eu queria concluir logo e fazer uma faculdade, dar uma estabilidade para meu filho." (Entrevista 3)

A palavra "estabilidade" vêm no sentido de buscar um futuro melhor, um desejo deles de poder proporcionar para si e seus familiares uma boa qualidade de vida, lembrando que $80 \%$ dos participantes consideram-se de classe média e $20 \%$ baixa.

\subsection{Concepções sobre o sucesso e fracasso escolar}

Nesta sessão o intuito é analisar que concepções os alunos do EJA têm acerca dos termos sucesso e fracasso escolar, afins de ter uma compreensão melhor desta temática. Através da pergunta “ O que você entende por Sucesso e Fracasso escolar?” os alunos trouxeram em seu discurso diversas críticas quanto ao termo, considerando-o pejorativo e preconceituoso, como é possível observar na fala abaixo:

"Eu acho que as pessoas rotulam demais, tipo "eu vou estudar para ser alguém na vida" e não podemos pensar assim, e também não podemos querer ser mais que os outros, temos que batalhar sim para conseguir nossos objetivos mas quando há falhas não podemos pensar que fracassamos. "(Participante 7)

"Muitas pessoas dizem que pessoal que faz o EJA não têm chance de fazer faculdade, eu discordo, se a pessoa tem interesse de aprender e batalhar ela consegue. Eu mesma tenho objetivos, pretendo fazer outro curso, exercer uma profissão." (Participante 9)

Pozzobon, Mahendra e Marin (2017) saliente que o rótulo têm o poder de conduzir os alunos a sentirem desprazer em estudar, desmotivando-os e reforçando o processo de insucesso escolar, por este motivo é necessário mudar o olhar quanto a terminologia. As reprovações e evasões são sim obstáculos que os alunos enfrentam, mas não consideram isso falhas ou fracasso, um dos participantes destaca que: 
“O sucesso precisa do fracasso se não ela não existiria. Fracasso não é quem roda, quem perde o emprego, fracasso é aquele que desiste, larga. Repetir de ano não é um fracasso é uma experiência, e sem experiência a gente não consegue o sucesso." (Participante 6)

Um dos participantes traz para a discussão sua visão quanto ao fenômeno, entendendo o fracasso não como uma falha, mas sim como a falta de "comprometimento" do aluno com os estudos, e demonstra uma certa preocupação quanto á isso no seu cotidiano escolar, principalmente com os colegas mais jovens:

"O que eu posso te dizer? assim, eu vejo essa juventude ai [...] falta muita maturidade, eles usam o linguajar ali que nunca na idade que eu tinha pensava em ouvir isso ai [...] Não prestam atenção no que os professores falam, atrapalha quem quer aprender, nesse lado eu vejo até uma certa preocupação, têm muitos ali que já rodaram umas duas três vezes já, tu não vê um comprometimento." (Participante 1)

Em revisão de literatura é possível observar discursos similares, principalmente vindo de professores, Morales e Alves (2016) contribuem com esse assunto com a ideia de que se o ensino não fizer sentido para o aluno, logo eles não despertarão o interesse, não havendo comprometimento, atenção e participação. Porém quanto aos motivos que levam ao aluno ao desinteresse não se podem afirmar, muito menos generalizar considerando que todos são diferentes e têm suas subjetividades, e tudo dependerá do contexto de cada um.

Em outras falas é possível constatar uma certa concordância com essa perspectiva:

"Sucesso tá sempre ali se a gente quiser, o fracasso é quando tu não te dá 100\%." (Participante 9)

"O sucesso têm muito a ver com o objetivo né, o fracasso é quando não atinge o objetivo, por algum motivo, falta de comprometimento ou falta de interesse." (Participante 5)

"Acho que depende da pessoa, até da própria motivação para alcançar os objetivos" (Participante 10)

Foi observado que a palavra "objetivo" parece em diversas respostas, mas nesse contexto a palavra toma um sentido singular sendo particular de cada um, não como algo já imposto pela instituição ou sociedade. 


\subsection{Envolvimento escolar na produção do sucesso ou fracasso educativo.}

Ao serem perguntados sobre quais eram suas percepções sobre a influência e envolvimento escolar na produção do sucesso e fracasso educativo, os alunos responderam de forma bem semelhante e direta. Em resposta, disseram que gostam muito da escola, principalmente dos professores, e isso de certa forma motiva eles a continuarem frequentando o ensino, segundo eles os profissionais do EJA são bem atenciosos, proporcionando além de um ensino coerente com suas necessidades, um ensino com zelo e carinho. O tratamento diferenciado aos alunos do EJA deriva da metodologia freireana no qual os profissionais se propõem a utilizar uma técnica de ensino que vai de encontro com a realidade do aluno (CAVALCANTE e CARDOSO, 2016).

Para os discentes a escola desta forma se torna motivadora, contribuindo significativamente para o desenvolvimento do processo ensino- aprendizagem e por consequência auxiliando-os rumo aos seus objetivos.

"nessa escola eles incentivam bastante a gente, os professores gostam bastante de conversar, têm alguns alunos que na sexta querem ir embora, eles puxam pra ficar, é bem tranquilo. Principalmente o pessoal do EJA. Como muitos trabalham durante o dia, eles acabam incentivando mais." (Participante 3)

"No meu ponto de vista a escola é uma segunda família, ela te acolhe, ela te recebe e tu têm que também fazer a tua parte né, ela é motivadora, ela abre as portas da casa para a gente ter um aprendizado. "(Participante 5)

“Eu acho que eles proporcionam o melhor para nós." (Participante 8)

"Motivam bastante, não só a gente a se formar como buscar conhecimento depois, não parar no tempo, essa escola pelo menos, nas outras não. Vejo mais isso no EJA do que no regular." (Participante 10)

Esse atendimento diferenciado aos alunos do EJA é bem visto pela maioria dos alunos, em contrapartida uma das entrevistadas traz uma crítica especificamente sobre isso, declara que: 
[...] em questão de passeio, de várias coisas legais na escola, eles nunca passam no EJA para perguntar se a gente quer. Eles entram no EJA só se tiver sobrando vaga, acho o tratamento com pessoal do EJA muito diferente. Eles só querem que a gente se forme logo e não vejo nenhuma motivação por parte dos professores. (Participante 4)

Neste ponto de vista compreende-se que nem todos alunos são adeptos a metodologia, necessitando de incentivos que vão além dos ensinamentos, uma preocupação a mais do que apenas a educação e o saber em sala de aula, mas das práticas e experiências que se pode vivenciar em um instituto educacional, como atividades extraclasses, projetos, e passeios, que são bem comuns no ensino regular.

\section{CONSIDERAÇÕES FINAIS}

O objetivo desta pesquisa foi Identificar as concepções de sucesso e fracasso escolar para alunos da Educação de Jovens e Adultos, para isso foi considerado além do que está escrito em estudos, acima de qualquer dado estatístico o foco foi ouvir e sentir o que os alunos nos trariam em seus discursos, pois nada é mais rico que a experiência e vivência.

Através da análise das falas dos discentes foi constatado que a percepção quanto a esse fenômeno educacional é amplo e bastante crítico, ao considerar os termos pejorativos os alunos manifestam sua indignação com a maneira que são vistos pela sociedade. Há então a necessidade dos professores e a sociedade pararem de rotulá-los, o significado do fracasso não deve se remeter de maneira restritiva, taxativa, ao limitar o nosso olhar estamos determinando o que o sujeito é ou será, quando o mesmo pode a qualquer momento mudar seu trajeto de vida, e os educandos do EJA é um exemplo perfeito, apesar de não concluírem os estudos na idade prevista, têm a possibilidade de retornar ao ambiente acadêmico e mudar seu percurso de uma forma adequada, justa e coerente com suas necessidades e demandam e o fracasso será parte do processo para o alcance do sucesso.

\section{REFERÊNCIAS BIBLIOGRÁFICAS}

ALMEIDA, Adriana de; CORSO, Angela Maria. A Educação de Jovens e Adultos: aspectos históricos e sociais. EDUCERE. 2015. 
ASBAHR, Flávia da Silva ; LOPES, Juliana S. A culpa é sua. Psicologia USP, São Paulo, v.17, n. 1, p. 53-73, 2004.

BANDURA, A; AZZI, R; POLYDORO, S. Teoria Social Cognitiva: conceitos básicos. Porto Alegre- RS: Artmed, 2006.

BARDIN, L. (2006). Análise de conteúdo (L. de A. Rego \& A. Pinheiro, Trads.). Lisboa: Edições 70. (Obra original publicada em 1977)

BRASIL. Artigo n. 208, da Emenda Constituicional n. 91 de 18/02/2016. O dever do Estado com a educação. Disponível em: https://www.senado.leg.br/atividade/const/con1988/con1988_18.02.2016/art_208_.asp. Acesso em: 24 abr. 2019.

BRASIL. Conselho Nacional de Educação. Resolução CNE/CEB n. 2/2001, de 11 set. 2001. Institui diretrizes nacionais para a Educação Especial na Educação Básica. Disponível em: http://portal.mec.gov.br/cne/arquivos/pdf/CEB0201.pdf. Acesso em: 24 abr. 2019.

BONO, V; QUARESMA, S. Aprendendo a entrevistar: como fazer entrevistas em Ciências Sociais. Revista Eletrônica dos Pós-Graduandos em Sociologia Política da UFSC. v. 2, n.1, p. 68-80, janeiro-julho, 2005.

CARVALHO, Roseli Vaz. A Juventude na Educação de Jovens e Adultos: uma categoria provisória ou permanente. In: IX Congresso Nacional de Educação- EDUCERE, III Encontro Sul Brasileiro de Psicopedagogia. Artigo, Porto Alegre: PUCPR, 2009.

CAVALCANTE, E; CARDOSO, M. Reflexões sobre a metodologia utilizada na educação de jovens e adultos: entre o real e o ideal. Revista Lugares de Educação., Bananeiras - PB, v. 6, n. 12, p.158-181, Jan.-Jul., 2016. 
CENTURION, D; GOMES, S. O Adolescer na EJA: a inserção dos adolescentes que fracassam no ensino regular. Ensino Em Re-Vista, v.22, n.2, p.363-375, jul./dez. 2015

CRESWELL, J. W. (2007). Projeto de pesquisa: métodos qualitativo, quantitativo e misto (2a ed., L. de O. Rocha, Trad.). Porto Alegre: Artmed. (Obra original publicada em 2003)

CURY, C. A educação básica no Brasil. Educ. Soc. Campinas. , v. 23, n. 80, setembro/2002.

DAMASCENO, M; COSTA, T; NEGREIROS, F. Concepções de Fracasso Escolar: um estudo com professores das cinco regiões brasileiras.Revista de Psicologia: Fortaleza, v.7 n.2, p. 8-21, jul./dez. 2016.

DOURADO, L; OLIVEIRA, J. A qualidade da educação: Perspectivas e Desafios. Cad. Cedes: Campinas vol. 29, n. 78, p. 201-215, maio/ago. 2009.

FRANCO, A. O mito da autoestima na aprendizagem escolar. Revista Semestral da Associação Brasileira de Psicologia Escolar e Educacional (ABRAPEE), v. 13, n;2, Julho/Dezembro de 2009.

GADOTTI, M. Perspectivas atuais da educação. São Paulo em Perspectiva: SP, 2000.

GOMES, A. Os significados que os alunos da EJA têm em relação à instituição escolar. Interagir: pensando a extensão: Rio de Janeiro, n. 20, p. 01-21, jan./dez. 2015

Instituto Brasileiro de Geografia e Estatística (IBGE). Censo demográfico de 2016. Disponível em: https://seriesestatisticas.ibge.gov.br/lista_tema.aspx?op=0\&no=4\&de $=57$. Acesso em: 26 abr. 2019

LOPES, A; TEIXEIRA, M. Projetos de Carreira, autoeficácia e sucesso escolar em ambiente multicultural. Revista Brasileira de Orientação Profissional: Lisboa- Portugal, v. 13, n. 1, p. 7-14, 2012. 
MEDEIROS, Maria do Socorro de Araújo. A Formação de Professores para a Educação de Adultos no Brasil: da história à ação. Palma de Malorca: Tese de Doutorado pela Universitat de les Illes Balears, 1999.

MILLONES, D; LEEUWEN, K; GHESQUIÈRE, P. Associations between Psychosocial Functioning and Academic Achievement: The Peruvian Case. Universitas Psychologica: v.12, n. 3, p. $725-737$.

MORALES, M; ALVES, F. O desinteresse dos alunos pela aprendizagem: uma intervenção pedagógica. Paraná, secretaria de educação. 2016

MOZZATO, A; GRZYBOVSKI, D. Análise de Conteúdo como Técnica de Análise de Dados Qualitativos no Campo da Administração: Potencial e Desafios. RAC: Curitiba, v. 15, n. 4, p. 731-747, Jul./Ago. 2011.

NAIFF, L; MONTEIRO, D. Educação de Jovens e Adultos em uma análise psicossocial: representações e práticas sociais. Psicologia \& Sociedade. V. 20, N. 3, P. 402-407, 2008.

NEGREIROS, F. et al. Análise psicossocial do fracasso escolar na Educação de Jovens e Adultos. Psicologia em Pesquisa: p. 1-11. 2017

Organização para a Cooperação e o Desenvolvimento Econômico. (2010). Overcoming school failure: Policies that work. Disponível em: http://www. oecd.org/education/school/45171670.pdf Acesso em: 29/04/2019.

PEZZI, F; DONELLI, T; MARIN, A. School Failure in the Perception of Adolescents, Parents and Teachers. Psico-USF: Bragança Paulista, v. 21, n. 2, p. 319-330, mai./ago. 2016

PICONEZ, S. Educação Escolar de Jovens e Adultos. Campinas, SP: Papirus, 2002.

POZZOBON, M; MAHENDRA, F; MARIN, A. Renomeando o Fracasso escolar. Psicologia Escolar e Educacional: SP. v. 21, n. 3, p. 387-396, 2017. 
ZAGO, N. Fracasso e sucesso escolar no contexto das relações família e escola: Questionamentos e tendências em sociologia da educação. Revista Luso-Brasileira: v. 2, n.3, p. $57-83.2011$ 